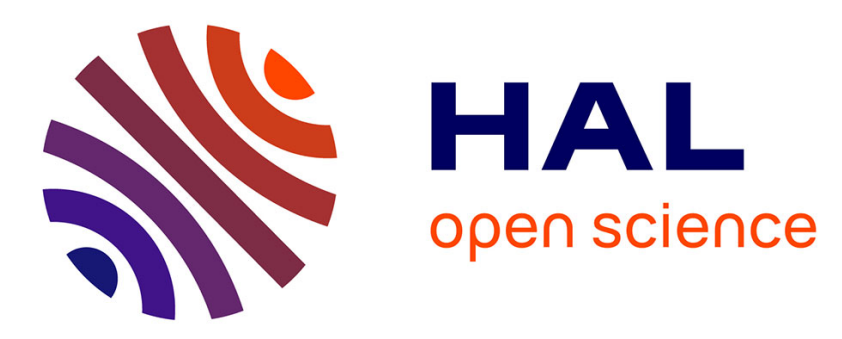

\title{
Thin phosphatidylcholine films as background surfaces with further possibilities of functionalization for biomedical applications
}

Lara Tauk, Thierry Thami, Lynda Ferez, Armagan Kocer, Jean-Marc Janot, Philippe Dejardin

\section{To cite this version:}

Lara Tauk, Thierry Thami, Lynda Ferez, Armagan Kocer, Jean-Marc Janot, et al.. Thin phosphatidylcholine films as background surfaces with further possibilities of functionalization for biomedical applications. Colloids and Surfaces B: Biointerfaces, 2013, 101, pp.189 - 195. 10.1016/j.colsurfb.2012.06.028 . hal-01688768

\section{HAL Id: hal-01688768 \\ https://hal.umontpellier.fr/hal-01688768}

Submitted on 28 Jan 2021

HAL is a multi-disciplinary open access archive for the deposit and dissemination of scientific research documents, whether they are published or not. The documents may come from teaching and research institutions in France or abroad, or from public or private research centers.
L'archive ouverte pluridisciplinaire HAL, est destinée au dépôt et à la diffusion de documents scientifiques de niveau recherche, publiés ou non, émanant des établissements d'enseignement et de recherche français ou étrangers, des laboratoires publics ou privés. 


\title{
1 Thin phosphatidylcholine films as background
}

\author{
2 surfaces with further possibilities of
}

\section{3 functionalization for biomedical applications.}

4

$5 \quad$ Lara Tauk ${ }^{1}$, Thierry Thami ${ }^{1}$, Lynda Ferez ${ }^{1}$, A. Kocer ${ }^{2,3}$, Jean-Marc Janot ${ }^{1}$, Philippe

$6 \operatorname{Déjardin}^{1 *}$

7

$8{ }^{1}$ Institut Européen des Membranes, Université Montpellier 2 (ENSCM, UM2, CNRS),

9 CC047, 2 Place Eugène Bataillon, F-34095 Montpellier Cedex 5 (France)

$10 \quad{ }^{2}$ Biomade Technology Foundation, Nijenborgh 4, 9747AG, Groningen, The Netherlands.

$11{ }^{3}$ Department of Biochemistry, Groningen Biomolecular Sciences and Biotechnology Institute,

12 University of Groningen, Nijenborgh 4, 9747 AG, Groningen, The Netherlands.

14 *Corresponding author, philippe.dejardin@iemm.univ-montp2.fr, Tel +33 467149121, Fax

$15+33467149119$.

16 
2 ABSTRACT Non-specific adsorption is a crucial problem in the biomedical field. To

3 produce surfaces avoiding this phenomenon, we functionalized thin $(7-180 \mathrm{~nm})$

4 poly(methylhydrosiloxane) (PMHS) network films at room temperature $\left(\approx 20^{\circ} \mathrm{C}\right)$ with

5 phospholipids (PL) bearing a phosphorylcholine head. Regardless of their mode of

6 preparation (casting or immersion), all surfaces appeared to be very hydrophilic with a captive

7 air-bubble contact angle stabilized around $40^{\circ}$. The thin films were protein-repellent in

8 phosphate saline buffer $\mathrm{pH} 7.4$ according to analysis by normal scanning confocal

9 fluorescence. Neither was any adsorption or spreading of L- $\alpha$-Phosphatidylcholine liposomes

10 on such films observed. In addition, amino functional groups could be easily attached to the

11 surface remaining available for further functionalization.

13 Keywords: biocompatibility; phosphorylcholine; phosphatidylcholine; biomaterials; PMHS;

14 anti-fouling 


\section{Introduction}

3

The efficient functioning of sensors for biomedical analysis is dependent on the integrity and accessibility of the surface-fixed molecule designed for molecular recognition, on the one hand, and on the surroundings designed for neutral behavior, especially to avoid nonspecific adsorption, on the other hand. Thus blocking buffers are proposed in diagnostic kits with for instance albumin[1,2]. In addition, fabrication of polymer films on solid supports with defined structures and properties such as uniformity, stability, and reproducibility is crucial in the development of thin-film chemical sensors. It is still difficult to fabricate ultrathin polymer films that are uniform, continuously defect free, and stable. Moreover, controlled growth of stable polymer films at the nanoscale level, which is important in many applications, remains a challenge. Some control of film thickness, uniformity, stability is needed to achieve reproducibility[3].

A crucial aspect in the design of biomaterials surfaces is to achieve control also over the interfacial interactions between the synthetic material/device and the biological medium[4, 5]. Protein-resistant ("non-fouling") surfaces are particularly important in the context of blood-contacting biomedical devices, and as non-interactive background for bio-diagnostic surfaces. There is a very limited number of effective non-fouling surfaces available to meet the challenges of practical applications [6]. Poly(ethylene glycol) (PEG) and oligo(ethylene glycol) (OEG) have been widely used to resist nonspecific protein adsorption $[7,8]$ owing to their ability to form a hydration layer via hydrogen bonds but the strength of these bonds decreases as the temperature increases[9]. Moreover, PEG or OEG can decompose in the presence of oxygen and transition metal ions[10]. Recently zwitterionic (sulfobetaine; carboxybetaine) materials have been found to exhibit ultralow protein adsorption $[11,12]$ 
1 (fibrinogen adsorption $<5 \mathrm{ng} \mathrm{cm}^{-2}$ ). This is due to the zwitterion structure which retains a

2 large amount of tenaciously held water independent of temperature because of hydration via

3 ionic solvation[13]. The interface is expected to be electrically neutral over a wide $\mathrm{pH}$ range

4 (5-9) with phosphate and sulfonate zwitterions while variations can be exploited with carboxy

5 groups. Coated surfaces with zwitterionic phospholipids have been shown to confer high

6 resistance to protein adsorption[14]. The mechanism of protein adsorption resistivity on the

7 phosphorylcholine modified surface is thought to be based on the interaction between water

8 and phosphorylcholine groups. It is reported that when the water fraction on the polymer

9 surface is maintained at a higher level, the proteins can contact the surface reversibly without

10 significant conformational changes[15]. The large amount of water around the

11 phosphorylcholine groups is thought to repel proteins and even prevent conformational

12 changes of the few adsorbed proteins[16-18].

Recently a zwitterionic trimethoxysilane was synthesized for direct grafting on oxidized silicon wafers[19]. In the present work we applied the strategy of surface anchoring a reactive poly(methylhydrosiloxane) (PMHS) network, as in the development of a sensor for nitroaromatics[20], followed by covalent grafting of phospholipids bearing the zwitterionic phosphorylcholine head on the polymer active sites $(\mathrm{SiH})$ via the hydrosilylation reaction

(Fig. 1a). X-ray photoelectron analysis was used to follow the reaction. The captive air bubble contact angle in water was measured to characterize the samples surface hydrophilicity. We considered especially thin PMHS films (10-200 nm), extending the previous study on films of thickness in the micrometer range[21], with the aim of creating low roughness surfaces not exhibiting the grooves shown in that previous work but conserving their proteinrepellent character. Protein adsorption was analyzed by the normal scanning confocal fluorescence technique. 
4

\section{Materials and Methods}

\subsection{Chemicals}

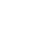

Both the precursors methyldiethoxysilane $\mathrm{HSi}\left(\mathrm{CH}_{3}\right)\left(\mathrm{OCH}_{2} \mathrm{CH}_{3}\right)_{2}(\mathrm{DH})$ and triethoxysilane $\mathrm{HSi}\left(\mathrm{OCH}_{2} \mathrm{CH}_{3}\right)_{3}(\mathrm{TH})$ were purchased from ABCR (Karlsruhe, Germany) and used as received. Water for substrate cleaning was obtained from a Milli-Q water purification apparatus (Millipore). Absolute ethanol for sol-gel synthesis was of synthesis grade purity. Trifluoromethanesulfonic acid $\mathrm{CF}_{3} \mathrm{SO}_{3} \mathrm{H}$ was purchased from Aldrich. Toluene was distilled before use for thin film hydrosilylation. The platinum-divinyltetramethyldisiloxane complex in xylene (PC072) (platinum concentration of about $0.1 \mathrm{M}$ assuming 2.4\% (w) Pt in xylene), also known as Karstedt's catalyst, was purchased from ABCR. 1,2-dilinoleoyl-sn-glycero-3phosphorylcholine (18:2 Cis) (PL) was purchased from AvantiPolarLipids. The molecule bears the zwitterionic phosphorylcholine head and two unsaturated cis carbon-carbon bonds on each of the two fatty chains. 3-(ethoxydimethylsilyl)-propyl amine (Aldrich, 588857) and hexamethyldisilazane were used as received.

\subsection{Proteins and labeling}

Bovine serum albumin (A-7638), cytochrome C (C-2506), $\alpha$-chymotrypsin (C-4129), avidin (A9275) were purchased from Sigma-Aldrich; some avidin from Fluka (No. 11368). Given their isoelectric point, at physiological pH 7.4, BSA (67 $\left.000 \mathrm{~g} \mathrm{~mol}^{-1}, \mathrm{pI} 5.6\right)$ is negative, $\alpha$-chymotrypsin (25 $300 \mathrm{~g} \mathrm{~mol}^{-1}$, pI 8.1) slightly positive, avidin (66 000g mol ${ }^{-1}$, pI 10) and cytochrome $\mathrm{C}$ (12 $400 \mathrm{~g} \mathrm{~mol}^{-1}$, pI 10.2) strongly positive. 
1 Labeling of proteins was performed with Alexa-fluor-594 succinimidyl ester (InvitroGen,

2 A30008). Typically $500 \mu \mathrm{L}$ of protein solution were added to dry fluorophore Alexa-594 in

3 molar ratio $1: 1$ and allowed to react for $0.5 \mathrm{~h}$ at $20^{\circ} \mathrm{C}$. Avidin was also labelled via previous

4 biotin-ethylenediamine hydrobromide (Sigma B9181) reaction with alexa succinimidyl ester

5 as described elsewhere [22]. The mixture was then put in an ad hoc microtube with filter

6 (Biospin P6) and centrifuged at $16000 \mathrm{~g}$ for $1 \mathrm{~min}$ according to the supplier of the kit

7 (Labelling kit A10239, InvitroGen). The labeling ratio [Alexa] / [protein] (0.3-0.5) was

8 determined from the UV absorbances at $280 \mathrm{~nm}$ where both the label $\left(\varepsilon_{280}\right.$-Alexa $=50400 \mathrm{M}^{-1}$

$\left.9 \mathrm{~cm}^{-1}\right)$ and protein absorb and at $590 \mathrm{~nm}$ where only the label $\left(\varepsilon_{590}=90000 \mathrm{M}^{-1} \mathrm{~cm}^{-1}\right)[23]$

10 absorbs. Protein solutions were prepared in $10 \mathrm{mM}$ sodium phosphate buffer $\mathrm{pH} 7.4$ with

$110.15 \mathrm{M} \mathrm{NaCl}$ in de-ionized water (MilliQ system, Millipore) and stored at $4^{\circ} \mathrm{C}$.

12

\subsection{Liposome preparation and labeling}

One hundred milligrams of L- $\alpha$-Phosphatidylcholine (Soy-20\%) (Avanti Polar Lipids Inc. 541601) was dissolved in $5 \mathrm{ml}$ of chloroform containing $100 \mu \mathrm{L}$ of a 1,1 '-dioctadecyl3,3,3',3'-tetramethylindodicarbocyanine perchlorate solution (Invitrogen Inc.) $(1 \mathrm{mg} / \mathrm{ml}$ in methanol). After chloroform had been thoroughly removed under vacuum, phosphate buffered saline (PBS, 10mM, pH 8.1, 150mM NaCl) was added and mixed in. Aggregated particles were then sonicated until complete dissolution. The mixture was then taken through a freezethaw procedure five times. This procedure involved freezing the solution by immersion in liquid nitrogen, followed by thawing by immersion in $60{ }^{\circ} \mathrm{C}$ water. After the freeze-thaw process, the vesicle suspension was divided into 10 samples of $500 \mu \mathrm{L}$, frozen once again by immersion in liquid nitrogen and stored at $-80^{\circ} \mathrm{C}$. Before use, the vesicle suspension was heated by immersion in $60^{\circ} \mathrm{C}$ water and regularized by extrusion through polycarbonate 
1 membrane filters (Avestin Inc.) of pore diameter $400 \mathrm{~nm}$ mounted in a mini-extruder (Avestin

2 Inc.). We subjected the samples to 11 passes through the membrane.

3

4

6

7

8

9

10

The same procedure without the label DiD was applied to obtain unlabeled liposomes whose size distribution was measured by photon cross-correlation spectroscopy (Nanophox, Sympatec - France).

\subsection{Methods of preparation of the support}

\subsubsection{Substrate cleaning and activation}

Silicon wafers $\mathrm{Si}(100)$ (ACM, France) square strips of $2 \times 2 \mathrm{~cm}^{2}$ were used as substrates for spin-coating deposition. To bond covalently the PMHS thin films to native oxide silica (thickness ca $2 \mathrm{~nm}$ ) and to glass surfaces, they were cleaned and activated with oxygen plasma for 60 seconds.

\subsubsection{PMHS film}

17

8

$$
\text { PMHS thin films were prepared at } 22 \pm 1^{\circ} \mathrm{C} \text { by sol-gel polymerisation of } \mathrm{DH} \text { and } \mathrm{TH}
$$
as crosslinker, as described elsewhere[24]. This procedure gave layers of reproducible homogeneity and thickness as controlled by ellipsometry (Plasmos SD 2300 ellipsometer (München Germany)) [25]. We used refractive index $n=1.4$ for PMHS.

\subsubsection{Grafting PMHS with phospholipids} a-by casting: the phospholipid solution was prepared under argon. $20 \mathrm{mg}$ of PL were dissolved in $8 \mathrm{~mL}$ of dry toluene $(2.5 \mathrm{mg} / \mathrm{mL})$, with additional $7 \mu \mathrm{L}$ of the Karstedt catalyst 
1 (xylene solution of platinum divinyltetramethyldisiloxane complex). The molar ratio of

2 phospholipid over hydrogenosilane group $\mathrm{SiH}$ was 1.5 . PMHS coated silicon wafers $(2 \times 2$

$\left.3 \mathrm{~cm}^{2}\right)$ and glass surfaces $\left(1.5 \mathrm{~cm}^{2}\right)$ were covered by $200 \mu \mathrm{L}$ and $80 \mu \mathrm{L}$ of phospholipid solution

4 respectively. The samples were kept for one hour under a cap to slowly evaporate the solvent

5 and then left in open air for quick evaporation.

7 for one hour.

For both methods, the samples were then rinsed successively in different toluene/chloroform mixtures from $100 / 0$ to $0 / 100$ ( $\%$ vol.) with a gap of $20 \%$ and dried under a stream of Argon. We will refer to the PMHS layer having reacted with PL as PL-PMHS( $h$ $\mathrm{nm})$ where $h$ is the PMHS initial thickness measured by ellipsometry.

\subsection{Techniques of characterization of the support}

\subsubsection{X-ray photoelectron spectroscopy}

The surface elemental compositions of unmodified and modified PMHS surfaces were analysed by X-ray photoelectron spectroscopy (XPS). The spectrophotometer (ESCALAB 250, Thermo Electron, UK) was equipped with a monochromatic $\mathrm{Al} \mathrm{K \alpha}(1486.6 \mathrm{eV})$ radiation source. The acceleration tension and power of X-ray source were $15 \mathrm{kV}$ and $100 \mathrm{~W}$, respectively. The samples were analysed at a pressure in the $10^{-9} \mathrm{mbar}$ range. The electron take-off angle with respect to the sample surface was $90^{\circ}$. The analysed spot size was approximately $400 \mu \mathrm{m}^{2}$. The XPS composition corresponds to depths of 5-10 nm. Survey scans $(0-1350 \mathrm{eV})$ at low resolution were performed to identify constitutive elements. High resolution $\mathrm{C}_{1 \mathrm{~s}}, \mathrm{Si}_{2 \mathrm{p}}, \mathrm{O}_{1 \mathrm{~s}}, \mathrm{~N}_{1 \mathrm{~s}}$ and $\mathrm{P}_{2 \mathrm{p}}$ spectra were recorded to obtain more detailed information 
1 about the nature of the surface. The peaks were fitted with Gauss-Lorentz curves. They

2 provided the various surface atomic ratios from the corresponding peak areas, by assuming

3 the total area corresponded to $100 \%$, after correction with the theoretical sensitivity factors

4 [26]. The spectra of both pristine PMHS and PL-PMHS were calibrated using the

5 hydrocarbon contaminant or alkane $\mathrm{C}_{1 \mathrm{~s}}$ peak set at $284.8 \mathrm{eV}$. In both cases, the peak of Si-

$6 \mathrm{CH}_{3}$ was found at a binding energy (BE) of $284.0 \mathrm{eV}$ in agreement with PDMS polymer at

$7 \quad 284.4 \mathrm{eV}[27]$.

8

$9 \quad$ 2.5.2 Captive air bubble contact angle in water

10

The samples were characterized by captive air-bubble $(7.6 \mu \mathrm{L})$ contact angle (GBX -

Digidrop, Romans, France). The contact angle was calculated after 1 min using computerized image analysis. The data are relative to the angle through the liquid as generally defined[28], in opposition to its complement angle to $180^{\circ}$ through air as used in a previous work[21]

$$
\text { 2.5.3 AFM }
$$

Atomic Force Microscopy (AFM) experiments were performed using a Dimension 3100 microscope equipped with a Nanoscope IIIa controller system (Digital Instruments, Veeco Metrology Group). AFM images were obtained by scanning in tapping mode in water or under ambient conditions in air using silicon SPM probes (stiffness $k \approx 2 \mathrm{~N} / \mathrm{m}$, resonance frequency of $67 \mathrm{kHz}$, pointeprobeplus, Nanosensors). The root mean square average roughness $\left(R_{q}\right)$ was analyzed with the Nanoscope software (version 5.31r1). 
The experiments were performed at $\mathrm{T}=19^{\circ} \mathrm{C}$ in a slit flow cell of thickness $\approx 100 \mu \mathrm{m}$

3 and flow rate corresponding to wall shear rate $1000 \mathrm{~s}^{-1}$. Confocal measurements[29, 30] with inverted microscope configuration were performed at $3 \mathrm{~cm}$ from the slit entrance. Interfacial concentration was evaluated as follows: the fluorescence signal $F_{\text {sol }}$ from solution at concentration $C$ is relative to an effective volume $V$ while the signal $F_{\text {surf }}$ from surface concerns interfacial concentration $\Gamma$ over area $A . F_{\text {surf }} \propto \Gamma A$ and $F_{\text {sol }} \propto C V$ therefore $\Gamma=$ $(V / A)\left(F_{\text {surf }} / F_{\text {sol }}\right) C$. In a previous paper[29] the order of magnitude of $V / A$ was estimated from

9 the focus radius for $A$ and $1 \mu \mathrm{m}^{3}$ taken as the confocal volume $V$. A more precise determination is obtained considering the adsorbed layer as a Dirac function of fluorescence[21]. Then $V / A=w_{D}$ is the area under the normalized fluorescence peak $f_{i}(y)=$ $F_{i}(y) / F_{i}(0)$ resulting from the convolution of the fluorescent interface positioned at $y=0$ with the laser beam.

\section{Results and Discussion}

\subsection{Physico-chemical characterization of PMHS and PL-PMHS films}

The ellipsometric thickness of PMHS film on oxidized wafers as a function of initial concentration of monomers $(\mathrm{DH}$ and $\mathrm{TH})$ is provided in Fig. 1b. The variation was linear with a slope of $95 \pm 4 \mathrm{~nm} \mathrm{M}^{-1}$. After hydrosilylation reaction had proceeded over one hour by means of casting or immersion the thickness of the PL-PMHS layer was measured and the hydrophilicity characterized by captive air bubble contact angle (Fig. 1c). Both techniques gave the same results suggesting the occurrence of a quick interfacial reaction over less than one hour and efficient removal of excess phospholipids in the casting method. An average 
1 angle of $40^{\circ}$ was observed whatever the initial PMHS thickness, much below the value of $90^{\circ}$

2 observed with hydrophobic PMHS. The ellipsometric thickness increased as expected after

3 reaction of the PMHS layer with phospholipids. Conditioning the samples overnight in Milli-

4 Q water gave rise to an additional increase of thickness. Over the range examined we can

5 attribute a mean $26 \%$ increase of thickness from the reaction with phospholipids and an $8 \mathrm{~nm}$

6 increase from conditioning the material in water. Conditioning the PL-PMHS for several days

7 in water led to rolling bubble $\left(0^{\circ}\right)$ possibly stabilized at a slightly higher contact angle (Fig.

8 1d).

9 
(a)

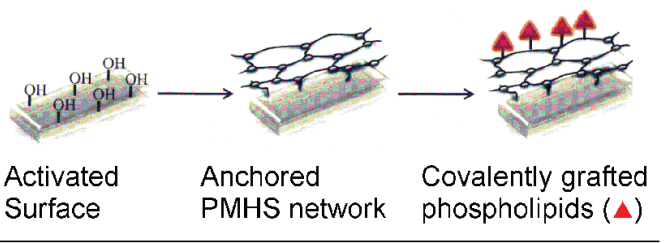

(b)

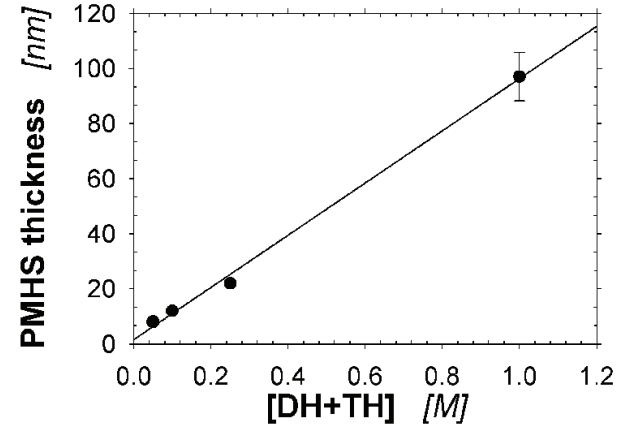

(c)

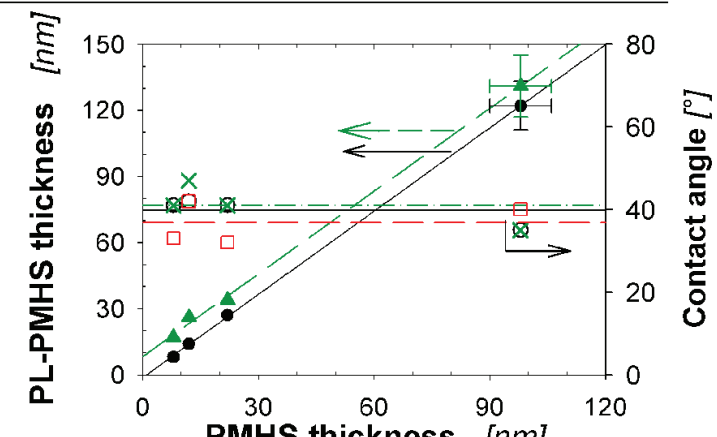

(d)

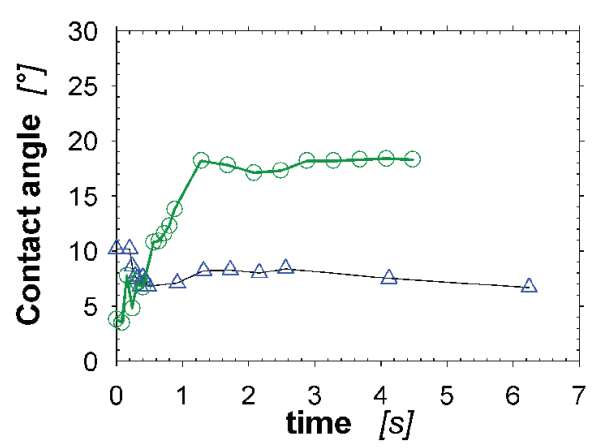

2 Figure 1 Method of surface treatment and physico-chemical characteristics of the films. (a)

3 Illustration of surface silanols of oxidized silicon wafer as anchoring points of PMHS network

4 for subsequent phospholipid grafting. (b) Thickness of PMHS film on oxidized silicon wafers

5 as a function of initial concentration of monomers. Slope $95 \pm 4 \mathrm{~nm} \mathrm{M}^{-1}$. Dispersion of data at

6 low concentration is of the order of the symbol size. (c left scale) PL-PMHS (reaction with PL

7 solution $2.5 \mathrm{mg} / \mathrm{mL}$ ) thickness after toluene/ chloroform rinsing ( $\bullet$; full line, slope $1.26 \pm$

$80.01)$ and additional overnight immersion in water ( $\boldsymbol{\Delta}$; dashed line, slope $1.25 \pm 0.03$, 
1 ordinate at the origin $8 \pm 2 \mathrm{~nm}$ ) as a function of original PMHS thickness. (c right scale)

2 Captive air bubble contact angle on PL-PMHS, created via casting (o) or immersion $(\times$,

3 wafer; $\square$, glass), as a function of initial PMHS thickness. (d) Examples of variation of contact

4 angle with time (rolling bubble over $\sim 1 \mathrm{~cm}$ ) for samples conditioned for several days in

5 water.

6

The structures of the PMHS and PL-PMHS films were examined by AFM (Fig. 2).

PMHS roughness was lower than $1 \mathrm{~nm}$ for a very thin layer $(12-20 \mathrm{~nm})$ while structures appeared for $125 \mathrm{~nm}$. Reaction of PL induced always an increase in roughness (Table 1). The $12 \mathrm{~nm}$ thin PMHS sample showed a roughness $R_{q}$ of $0.4 \mathrm{~nm}$ with a few defects. PL grafting induced an increase of roughness to $2.03 \mathrm{~nm}$ as measured in air. Immersion in water decreased the roughness to $1.28 \mathrm{~nm}$. This may be partly due to the reorganisation of phospholipids chains in the presence of an aqueous medium in order to minimise the free energy of the system. The minimum $0.9 \mathrm{~nm}$ for the PL-PMHS roughness was found for $c a .20$ nm thick PMHS.

Profiles

$h(\mathrm{~nm})$

PMHS

12
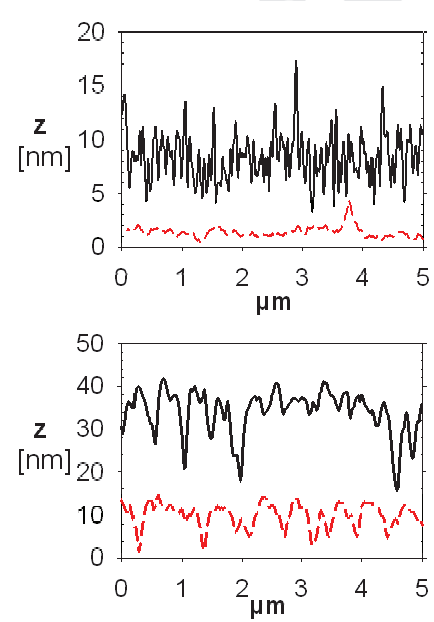

125
PMHS (AFM in air)

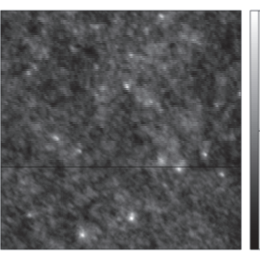

$4 \mathrm{~nm}$

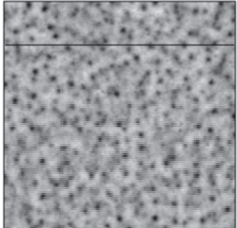

PL-PMHS

(AFM in air)

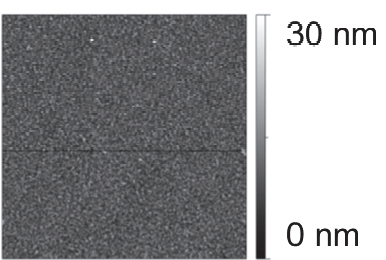

$25 \mathrm{~nm}$

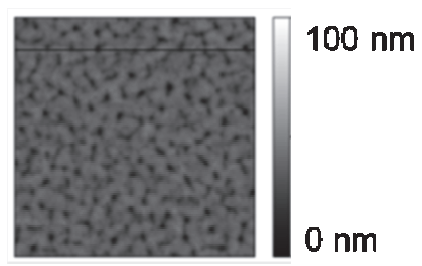


2 Figure 2 Characterization of the films by atomic force microscopy. AFM pictures $(5 \mu \mathrm{m} \times 5$

3

4 5

\begin{tabular}{ccc}
\hline $\begin{array}{c}h(\mathrm{PMHS}) \\
(\mathrm{nm})\end{array}$ & $\begin{array}{c}R_{q} \text { (PMHS) } \\
(\mathrm{nm})\end{array}$ & $(\mathrm{nm})$ \\
\hline 12 & 0.40 & 2.03 \\
\hline 20 & 0.60 & 0.90 \\
\hline 125 & 2.5 & 5.6
\end{tabular}
$\mu \mathrm{m}$ ) of PMHS layers (thickness $h$ ) and of their derived PL-PMHS layers. Corresponding profile samples of PMHS (dashed line) and PL-PMHS (full line).

6 Table 1 Roughness $R_{q}$ over $10 \mu \mathrm{m} \times 10 \mu \mathrm{m}$ samples of PMHS and derived PL-PMHS for 7 different initial PMHS thickness $h$.

8 
2

3

5

6

7

The wettability behaviour of the PL-PMHS surfaces (Fig. 1c-d) was indicative of a probable protein-repellent character. We investigated protein adsorption from single protein solution in PBS buffer pH 7.4 (avidin, bovine serum albumin (BSA), $\alpha$-chymotrypsin and cytochrome-C). Avidin is a model of a very stable hard protein. As most surfaces are negative, we considered preferably positive proteins at neutral $\mathrm{pH}$, to check the surface passivation with respect to protein adsorption. It should be borne in mind however that the ionic strength of PBS buffer is not small with $0.15 \mathrm{M} \mathrm{NaCl}$. Conversely the negative BSA can be viewed as a soft protein model, able to be adsorbed and denatured on many materials whatever their charge, thus a good candidate to check for possible hydrophobic interactions with surfaces. Indeed, this protein is often used in blocking buffers to prevent subsequent nonspecific adsorption.

The protein-repellent character of the PL-PMHS(20 nm) surface was checked in the configuration of flowing solutions in a slit. No adsorption of $\alpha$-chymotrypsin and cytochrome-C was observed (Fig. 3a). 
(a)

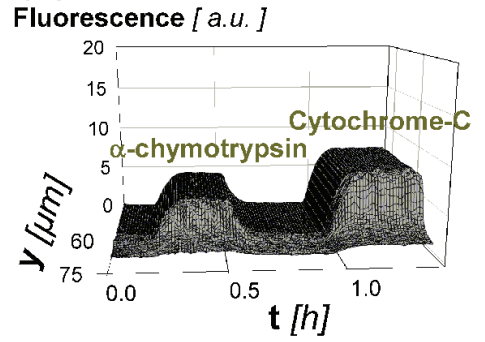

(b) 160

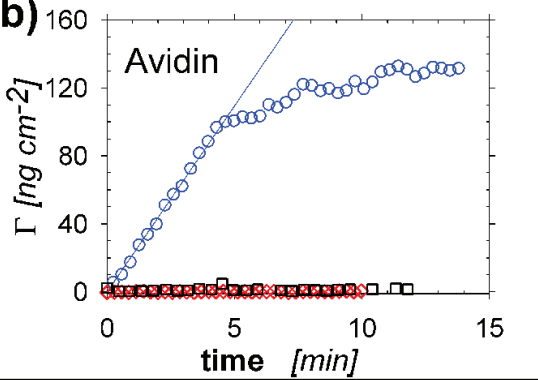

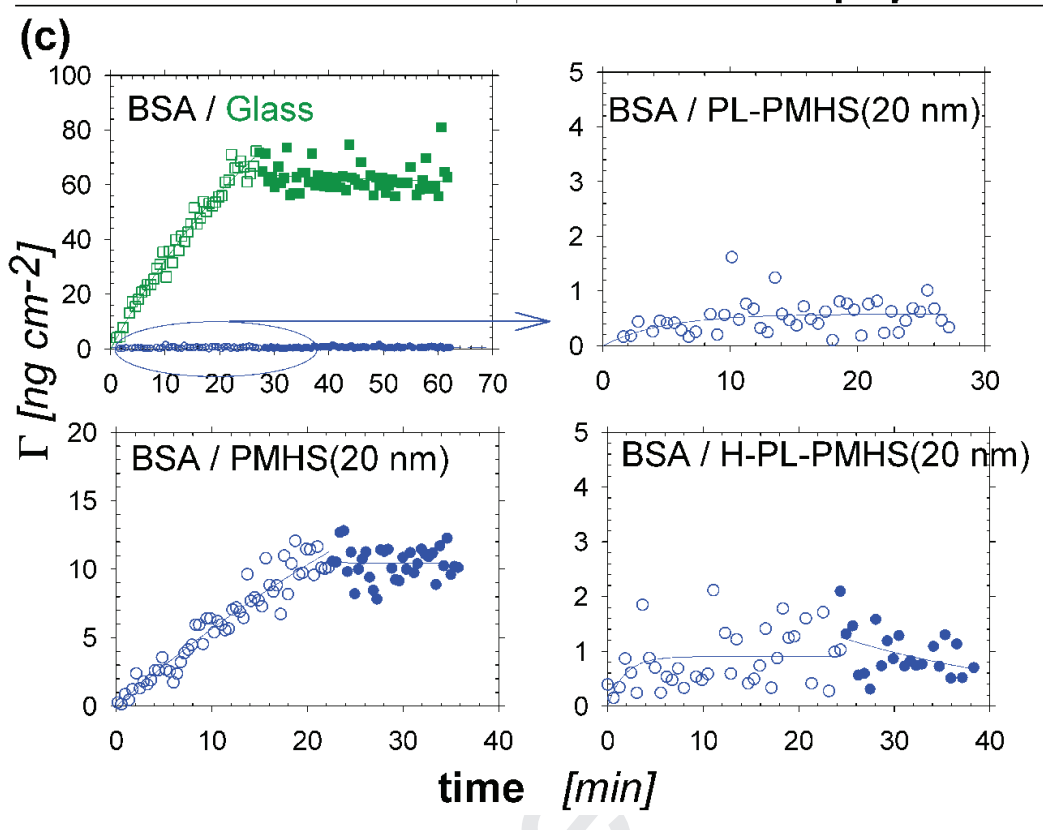

1

2 Figure 3 Adsorption under laminar flow conditions with wall shear rate $\gamma=1000 \mathrm{~s}^{-1}$. Closed symbols for the buffer rinsing step. (a) 3D graphs of successive flows of $\alpha$-chymotrypsin and treated with HMDS. 
The adsorption of avidin was examined on different PL-PMHS substrates derived

2 from the PMHS initial thicknesses of $7 \mathrm{~nm}$ and $180 \mathrm{~nm}$ (Fig. 3b). The interfacial

3 concentration was 1.2 and $0.1 \mathrm{ng} \mathrm{cm}^{-2}$ respectively, with dispersion around $1 \mathrm{ng} \mathrm{cm}^{-2}$. Let us

4 recall that there was a slight displacement in the plane of substrate between the normal

5 scannings to avoid repetitive exposure to the laser beam which could induce a photobleaching

6 effect. This procedure constituted then also an examination of the interface homogeneity.

7 Conversely, adsorption on sulfochromic acid treated glass was large with an initial linear

8 variation up to $c a$. $0.1 \mu \mathrm{g} \mathrm{cm}^{-2}$. The initial kinetic constant $k$ was $7.4 \times 10^{-5} \mathrm{~cm} \mathrm{~s}^{-1}$. With $D \approx 6$

$9 \quad 10^{-7} \mathrm{~cm}^{2} \mathrm{~s}^{-1}$, the transport limited constant $k_{L e v}$ is $2.6510^{-4} \mathrm{~cm} \mathrm{~s}^{-1}$. Applying the expression

$10[31,32] k_{a}=k\left(\mathrm{~b}_{1} u+1\right)\left(\mathrm{b}_{2} u+1\right) /\left((u-1)\left(\mathrm{a}_{1} u-1\right)\right)$, where $u=k / k_{\text {Lev }}$ and numerical coefficients

$11 \mathrm{a}_{1}=0.556, \mathrm{~b}_{1}=-0.681, \mathrm{~b}_{2}=-0.0484$, led to $k_{a} \approx 1.0 \times 10^{-4} \mathrm{~cm} \mathrm{~s}^{-1}$. In any case, the

12 phospholipid treatment was very efficient in preventing avidin adsorption, even at very small

13 thickness of PMHS (7 nm), exhibiting the good quality of the coverage and the corresponding

14 screening of the substrate.

15 The adsorption of Alexa-BSA was studied on PMHS(20 nm), PL-PMHS(20 nm) and

16 PL-PMHS followed by HMDS capping, denoted H-PL-PMHS(20 nm) (Fig. 3c). All surfaces

17 were immersed overnight in water and exposed to flowing buffer and solution with

18 sulfochromic acid treated glass as the other face. Whatever the surface, when adsorption

19 occurred no rapid desorption was observed by flowing buffer. The PMHS surface exhibited

some adsorption, $10 \mathrm{ng} / \mathrm{cm}^{2}$ over $20 \mathrm{~min}$ without a plateau $\left(k=1.010^{-6} \mathrm{~cm} \mathrm{~s}^{-1}\right)$. The H-PL-

PMHS showed a very small interfacial concentration $\left(\Gamma=0.8 \pm 0.5 \mathrm{ng} / \mathrm{cm}^{2}\right)$ comparable to

$0.5 \pm 0.3 \mathrm{ng} / \mathrm{cm}^{2}$ observed on PL-PMHS. It might reflect the burying of the trimethyl groups

medium thus preventing hydrophobic interactions with the protein. 
Our studies showed that phosphorylcholine modified PMHS layers experienced almost

2 "zero" protein adsorption. The decrease due to phosphorylcholine groups agrees also with

3 previous studies to improve the biocompatibility of poly(dimethylsiloxane) (PDMS)[33]. The

4 polymer of 2-methacryloyloxyethyl phosphorylcholine (MPC) was grafted by surface-

5 initiated photo-induced radical polymerization. The in vitro single protein adsorption on the

6 poly(MPC)-grafted PDMS decreased 50-75\% compared to the unmodified PDMS. On

7 poly(ether-ether-ketone) (PEEK) treated with MPC, BSA adsorption studies[34] showed a

8 significant effect of MPC till $90 \%$ adsorption reduction with respect to PEEK.

$9 \quad$ Adsorption of labeled (DiD) liposomes of L- $\alpha$-Phosphatidylcholine (diameter 400 nm)

10 was measured by scanning confocal fluorescence as for the proteins. Based on an average area

11 per head of $0.5 \mathrm{~nm}^{2}$ or diameter per head of $0.8 \mathrm{~nm}$, the adsorption at different interfaces is

12 shown in Fig. 4.

13
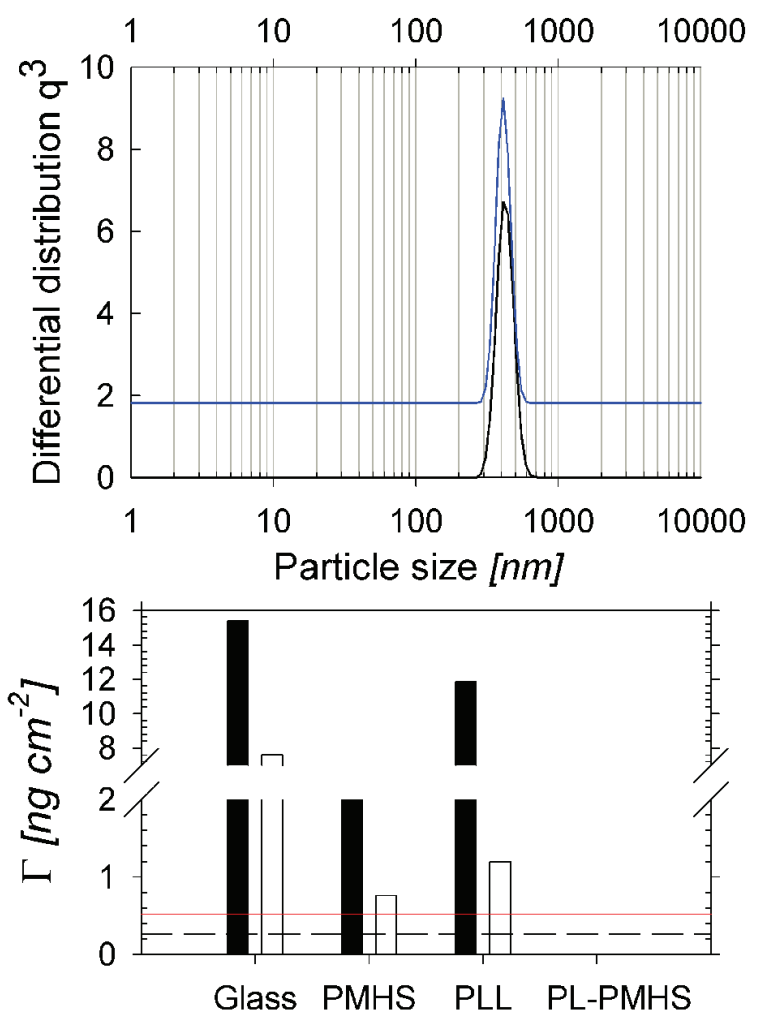
1 Figure 4 Characterization of liposomes and of their interaction with surfaces. (top) Photon cross-correlation spectroscopy of unlabeled L- $\alpha$-Phosphatidylcholine liposomes showing the reproducibility of the size $400 \mathrm{~nm}$ in the preparation. (bottom) Adsorption-spreading of

4 labelled liposomes on piranha treated glass, PMHS, poly(L-Lysine) (PLL) and PL-PMHS,

5 after one (full bar) and a few rinsings (empty bar). Horizontal lines correspond to estimated

6 monolayer (dashed line) and bilayer coverages (full line).

7

It can be seen that PL-PMHS constitutes a repellent surface with respect to L- $\alpha-$ Phosphatidylcholine liposomes, despite this lipid being not just a pure simple lipid but a mixture of lipids (24\% PC, 18\% Phosphatidylethanolamine, 11.5\% Phosphatidylinositol, 4.3 \% Phosphatidic acidA, 4.6\% LysoPC and some other unknown lipids).

\subsection{Functionalization of PL-PMHS Surface}

The XPS analysis after PMHS hydrosilylation with PL exhibited the side reaction with water giving silanol groups, which may evolve to siloxane bridges too. Such interfacial silanols could be available for subsequent reaction. Their presence was checked by reaction of a monoethoxy silane coupling agent bearing alexa as fluorescent probe (Scheme 1). Indeed, we observed a high fluorescence signal thus confirming the possibilities of chemical functionalization at such surfaces having an inert background of C18-phospholipids bearing a phosphorylcholine head. No coupling reaction occurred after pretreatment of PL-PMHS with hexamethyldisilazane (HMDS) as the silanols were neutralized by bulky trimethylsilyl groups. 


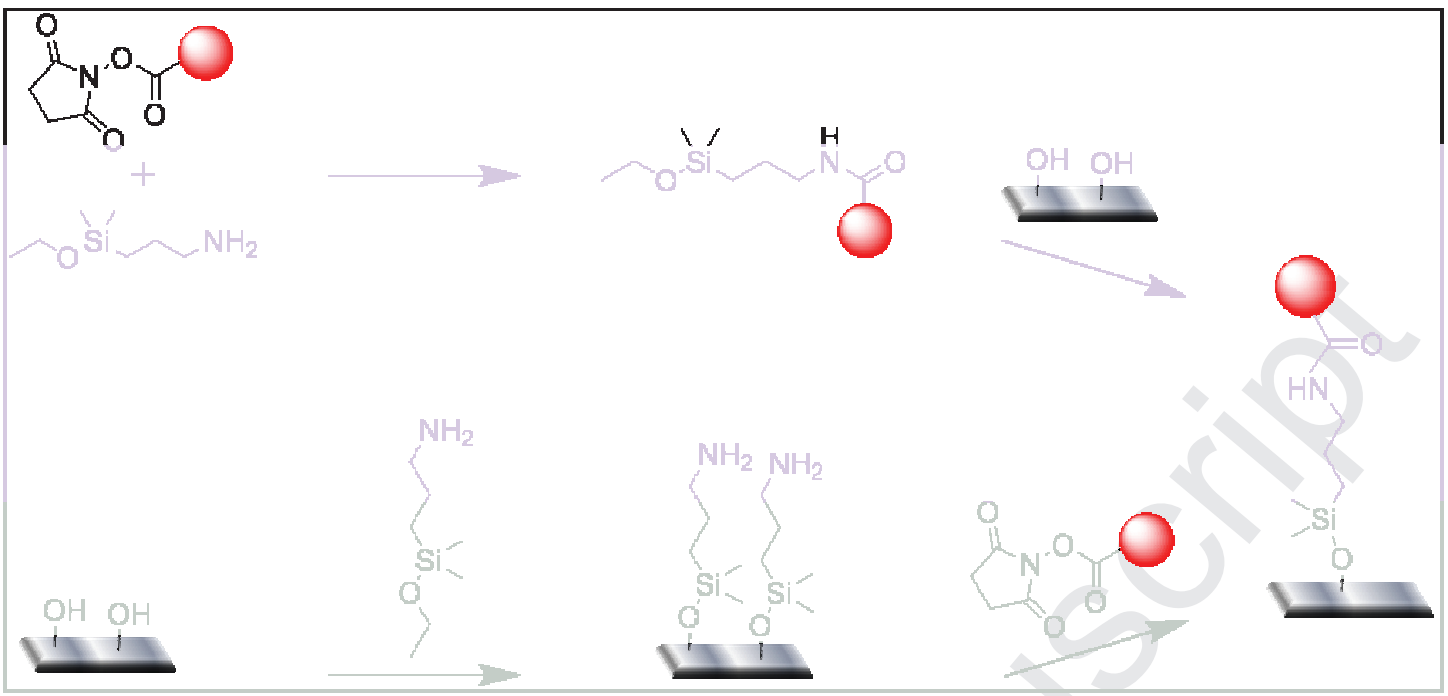

2 Scheme 1 Grafting reaction of Alexa, sketched as a big sphere, to surface silanols. (top) via previous formation of amide link between alexa and monoethoxy silane coupling agent and (bottom) via previous reaction of surface silanols with aminosilane.

5

PMHS did not exhibit any coupling reaction with alexa monoethoxy silane in toluene / ethanol (70/30), thus suggesting the relative stability of the interfacial hydrogenosilane ( $\mathrm{SiH})$ functional groups in the absence of water and catalyst. Moreover, this demonstrates that the Karstedt'catatyzed side reaction of $\mathrm{SiH}$ with water plays a major role in the formation of interfacial silanol on such PL-PMHS surface. After coupling the alexa probe, the silanol concentration can be thus estimated by assuming that the coupling reaction is total. According to the method developed above for determination of interfacial concentration, the mean degree of functionalization of the PL-PMHS layer was measured to be $3.0 \times 10^{-2} \mathrm{~nm}^{-2}$. Assuming that all molecules were grafted at the interface the mean distance between the sites was $5.7 \mathrm{~nm}$. This order of magnitude is acceptable for a quite dense packing of proteins on a neutral background and can be probably modified by changing the experimental conditions. In addition, we showed that the silanols of the interface could react also with aminomonoethoxysilane to provide a phosphorylcholine background surface with amino 
1 groups available for amide junctions (Scheme 1). This was carried out with the alexa ester

2 leading to the same interface as before with the same site density.

3

4 4. Conclusion

Polymethylhydrosiloxane anchored on an activated oxidized silicon wafer or glass can

be deposited as a very thin film of low roughness and functionalized with phospholipids bearing a phosphorylcholine head. The functionality of the surface was analyzed by XPS and the correlated wettability change determined by contact angle measurements with captive air bubble. The new interface was observed to be very hydrophilic and protein-repellent at neutral $\mathrm{pH}$ in phosphate saline buffer. L- $\alpha$-Phosphatidylcholine liposomes containing different phospholipids could not bind to such interfaces. Thus tailored surfaces can be produced to fix specific cells with appropriate functionalization. As the stiffness is a pertinent parameter in cell spreading[35], one perspective would be to vary the $\mathrm{DH} / \mathrm{TH}$ ratio in the synthesis of the PMHS films with better control of water in subsequent grafting. We have shown that the silanol groups originating from the side-reaction with traces of water provided possibilities for further functionalization. The prevention of protein adsorption is attributed to the zwitterionic character of the phosphorylcholine head which maintains a water-rich layer at the interface. We found that a $20 \mathrm{~nm}$ thick PMHS layer led to very flat surfaces with roughness less than 1 $\mathrm{nm}$. We have shown finally that the protein-repellent interface can be easily provided with amine functional groups. Therefore such protein-repellent interfaces can be useful in the biomedical domain, e.g. for biosensors, biomaterials and cell culture, by reducing strongly the non-specific adsorption, on the one hand, and offering in addition possibilities for grafting desired functions, on the other hand. Moreover, the covalent coverage with phospholipids and the sites for further functionalization are generated in a one step process. 
Acknowledgments This work was especially supported by FP7 European grant NMP214538 (BISNES project; Coord. D. Nicolau). We are grateful to M. Ramonda (LMCP, UM2) for the AFM pictures, to Valérie Flaud (XPS technological Platform, UM2) for XPS spectra and to F. Pichot (UM2) for access to clean room and ellipsometry.

\section{References}

[1] H. Ogi, Y. Fukunishi, H. Nagai, K. Okamoto, M. Hirao, M. Nishiyama, Biosens. Bioelectron. 24 (2009) 3148-3152.

[2] M. Holmberg, X.L. Hou, Colloids Surf., B 84 (2011) 71-75.

[3] J.W. Grate, R.A. McGill, Anal. Chem. 67 (1995) 4015-4019.

[4] M. Salim, S.L. McArthur, S. Vaidyanathan, P.C. Wright, Mol. Biosyst. 7 (2011) 101115 .

[5] W. Feng, X. Gao, G. McClung, S.P. Zhu, K. Ishihara, J.L. Brash, Acta Biomater. 7 3692-3699.

[6] K. Prime, G. Whitesides, Science 252 (1991) 1164.

[7] L.Y. Li, S.F. Chen, S.Y. Jiang, J. Biomater. Sci., Polym. Ed. 18 (2007) 1415-1427.

[8] F. Yan, P. Dejardin, J.N. Mulvihill, J.P. Cazenave, T. Crost, M. Thomas, C. Pusineri, J. Biomater. Sci., Polym. Ed. 3 (1992) 389-402.

[9] E.E. Dormidontova, Macromolecules 35 (2002) 987-1001.

[10] E. Ostuni, R.G. Chapman, R.E. Holmlin, S. Takayama, G.M. Whitesides, Langmuir 17 (2001) 5605-5620.

[11] W. Yang, S.F. Chen, G. Cheng, H. Vaisocherova, H. Xue, W. Li, J.L. Zhang, S.Y. Jiang, Langmuir 24 (2008) 9211-9214.

[12] Z. Zhang, S.F. Chen, S.Y. Jiang, Biomacromolecules 7 (2006) 3311-3315.

[13] W. Yang, H. Xue, W. Li, J.L. Zhang, S.Y. Jiang, Langmuir 25 (2009) 11911-11916.

[14] D. Chapman, Langmuir 9 (1993) 39-45.

[15] K. Ishihara, M. Takai, J. R. Soc. Interface 6 (2009) S279-S291.

[16] K. Ishihara, H. Nomura, T. Mihara, K. Kurita, Y. Iwasaki, N. Nakabayashi, J. Biomed. Mater. Res. 39 (1998) 323-330.

[17] Q. Sheng, K. Schulten, C. Pidgeon, J. Phys. Chem. 99 (1995) 11018-11027.

[18] T. Goda, J. Watanabe, M. Takai, K. Ishihara, Polymer 47 (2006) 1390-1396.

[19] L.X. Wu, Z. Guo, S. Meng, W. Zhong, Q.G. Du, L.S.L. Chou, ACS Applied Materials \& Interfaces 2 (2010) 2781-2788.

[20] K. Amro, S. Clement, P. Dejardin, W.E. Douglas, P. Gerbier, J.M. Janot, T. Thami, J. Mater. Chem. 20 (2010) 7100-7103.

[21] L. Ferez, T. Thami, E. Akpalo, V. Flaud, L. Tauk, J.M. Janot, P. Dejardin, Langmuir 27 (2011) 11536-11544.

[22] S. Balme, J.-M. Janot, P. Dejardin, P. Seta, Journal of Photochemistry and Photobiology A: Chemistry 184 (2006) 204-211.

[23] M.D. Melamed, N.M. Green, Biochem. J. 89 (1963) 591-\&.

[24] G. Nasr, H. Bestal, M. Barboiu, B. Bresson, T. Thami, J. Appl. Polym. Sci. 111 (2009) 2785-2797. 
[25] T. Thami, B. Bresson, C. Fretigny, J. Appl. Polym. Sci. 104 (2007) 1504-1516.

[26] J.H. Scofield, J. Electron Spectrosc. Relat. Phenom. 8 (1976) 129-137.

[27] G. Beamson, D. Briggs, High resolution XPS of organic polymers, Wiley, Chichester, 1992.

[28] S.J. Hong, F.M. Chang, T.H. Chou, S.H. Chan, Y.J. Sheng, H.K. Tsao, Langmuir 27 (2011) 6890-6896.

[29] J.-M. Janot, M. Boissiere, T. Thami, E. Tronel-Peyroz, N. Helassa, S. Noinville, H. Quiquampoix, S. Staunton, P. Dejardin, Biomacromolecules 11 (2010) 1661-1666.

[30] S. Balme, J.-M. Janot, P. Dejardin, E.N. Vasina, P. Seta, J. Membr. Sci. 284 (2006) 198-204.

[31] S. Noinville, J. Vidic, P. Dejardin, Colloids Surf., B 76 (2010) 112-116.

[32] P. Dejardin, E.N. Vasina, Colloids Surf., B 33 (2004) 121-127.

[33] T. Goda, T. Konno, M. Takai, T. Moro, K. Ishihara, Biomaterials 27 (2006) 51515160 .

[34] M. Kyomoto, T. Moro, Y. Takatori, H. Kawaguchi, K. Nakamura, K. Ishihara, Biomaterials 31 (2010) 1017-1024.

[35] K.F. Ren, L. Fourel, C.G. Rouviere, C. Albiges-Rizo, C. Picart, Acta Biomater. 6 (2010) 4238-4248. 


\section{Captions to illustrations}

2

3 Figure 1 Method of surface treatment and physico-chemical characteristics of the films. (a)

4 Illustration of surface silanols of oxidized silicon wafer as anchoring points of PMHS network

5 for subsequent phospholipid grafting. (b) Thickness of PMHS film on oxidized silicon wafers

6 as a function of initial concentration of monomers. Slope $95 \pm 4 \mathrm{~nm} \mathrm{M}^{-1}$. Dispersion of data at

7 low concentration is of the order of the symbol size. (c left scale) PL-PMHS (reaction with PL solution $2.5 \mathrm{mg} / \mathrm{mL}$ ) thickness after toluene/ chloroform rinsing ( $\bullet$; full line, slope $1.26 \pm$ $0.01)$ and additional overnight immersion in water $(\boldsymbol{\Delta}$; dashed line, slope $1.25 \pm 0.03$, ordinate at the origin $8 \pm 2 \mathrm{~nm}$ ) as a function of original PMHS thickness. (c right scale) Captive air bubble contact angle on PL-PMHS, created via casting (o) or immersion $(\times$, wafer; $\square$, glass), as a function of initial PMHS thickness. (d) Examples of variation of contact angle with time (rolling bubble over $\sim 1 \mathrm{~cm}$ ) for samples conditioned for several days in water.

Figure 2 Characterization of the films by atomic force microscopy. AFM pictures $(5 \mu \mathrm{m} \times 5$ $\mu \mathrm{m})$ of PMHS layers (thickness $h$ ) and of their derived PL-PMHS layers. Corresponding profile samples of PMHS (dashed line) and PL-PMHS (full line).

Figure 3 Adsorption in laminar flow conditions with wall shear rate $\gamma=1000 \mathrm{~s}^{-1}$. Closed symbols for the buffer rinsing step. (a) 3D graphs of successive flows of $\alpha$-chymotrypsin and cytochrome C solutions (150 nM) with intermediate flow of PBS buffer showing no adsorption on the wall of PL-PMHS covered oxidized silicon wafer (foreground, $\mathrm{y} \approx 67 \mu \mathrm{m}$ ). (b) avidin on (o $\bullet$ ) sulfochromic acid treated glass, $\mathrm{C}_{\mathrm{b}}=5.0 \mu \mathrm{g} / \mathrm{mL}$; ( $\square$ ) PL-PMHS(7 nm), $\mathrm{C}_{\mathrm{b}}$ $=10 \mu \mathrm{g} / \mathrm{mL}, \Gamma=1.2 \pm 0.9(\mathrm{SD}) \mathrm{ng} \mathrm{cm}{ }^{-2} ;(\diamond)$ PL-PMHS(180 nm), $\mathrm{C}_{\mathrm{b}}=5.0 \mu \mathrm{g} / \mathrm{mL}, \Gamma=0.1$ $\pm 0.9 \mathrm{ng} \mathrm{cm}^{-2}$; (c) BSA adsorption kinetics on different surfaces, $\mathrm{C}_{\mathrm{b}}=10 \mu \mathrm{g} / \mathrm{mL}$ : (top left) ( $\square$ ) 
1 sulfochromic acid treated glass, (o) PL-PMHS(20 nm), shown at a different scale on (top

2 right). $\Gamma=0.5 \pm 0.3 \mathrm{ng} \mathrm{cm}^{-2}$; (bottom left) PMHS(20 nm); (bottom right) PL-PMHS(20 nm)

3 treated with HMDS.

4

5 Figure 4 Characterization of liposomes and of their interaction with surfaces. (top) Photon

6 cross-correlation spectroscopy of unlabeled L- $\alpha$-Phosphatidylcholine liposomes showing the

7 reproducibility of the size $400 \mathrm{~nm}$ in the preparation. (bottom) Adsorption-spreading of

8 labelled liposomes on piranha treated glass, PMHS, poly(L-Lysine) (PLL) and PL-PMHS.

9 After (full bar) one and (empty bar) a few rinsings. Horizontal lines correspond to estimated

10 (dashed line) monolayer and (full line) bilayer coverages.

12 Scheme 1 Grafting reaction of Alexa, sketched as a big sphere, to surface silanols. (top) via

13 previous formation of amide link between alexa and monoethoxy silane coupling agent and

14 (bottom) via previous reaction of surface silanols with aminosilane.

15

- Simple method to build a thin phospholipid layer covalently linked to a polymer network

17 - From phospholipids, building of a stable background dense layer of phosphorylcholine

18 heads.

19 - Possibilities of additional routine chemistry for functionnalization over the

20 phosphorylcholine background. 


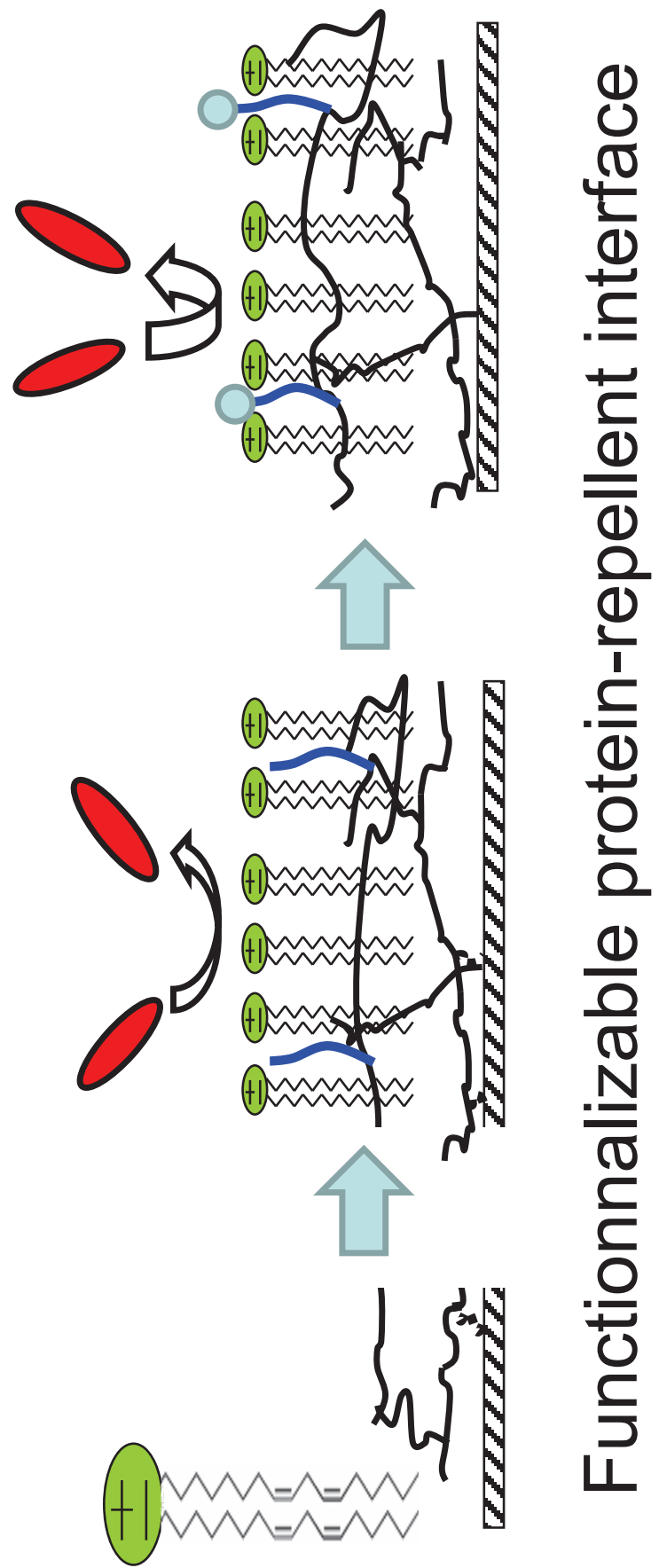

